\title{
Progresses on Thermodynamic Properties of the Systems Containing Lithium and Borate Ions by Isopiestic Method
}

\section{Yujuan $\mathrm{CaO}^{1}$, Long $\mathrm{Li}^{1}$, Shangqing Chen ${ }^{1}$, Yafei Guo ${ }^{1,2, a}$, Lingzong Meng ${ }^{1,3}$, Tianlong Deng ${ }^{1}$}

${ }^{1}$ Tianjin Key Laboratory of Marine Resources and Chemistry, College of Chemical Engineering and Materials Science at TUST, Tianjin 300457, China

${ }^{2}$ College of Chemistry and Materials Science, Northwest University, Xi'an 710127, China

${ }^{3}$ School of Chemistry and Chemical Engineering, Linyi University, Linyi 276000, China

a Corresponding author: E-mail: guoyafei@tust.edu.cn, Fax: 86-22-60602963.

Keywords: Isopiestic Method; Thermodynamic Property, Lithium Salts

\begin{abstract}
Isopiestic method is a common experimental method used in the field of the thermodynamic property of electrolyte solutions. The principle of isopiestic method, the development of isopiestic equipment and the application of isopiestic method in the field of thermodynamic properties of aqueous solutions containing lithium and borate ions have been summarized. The Pitzer single salt parameters and mixing ion interaction parameters containing lithium, chloride, sulfate, borate ions at different temperatures and systems were introduced in details. The latest developments on thermodynamic properties of borate solution by isopiestic method were analyzed, and the new trends in the future on the thermodynamics of borate electrolyte solutions by isopiestic method were also pointed out.
\end{abstract}

\section{Introduction}

Thermodynamic properties of the electrolyte solution, significant for the exploitation of salt brine, marine resource and the research on life and environment involved electrolyte solution, is an important part of the chemical solution theory [1]. Therefore, study on the thermodynamic properties of electrolyte solutions has been taken seriously by chemistry and chemical engineering industry. Currently, the domestic and foreign methods used in the research of thermodynamic properties of electrolyte solution, are mainly isopiestic, chemical potential and calorimetry method, and so on. Compared with calorimetry and chemical potential method, isopiestic method has been widely applied to the study on thermodynamic properties of salt-water system, owing to its high accuracy, few restrictions, and it is easy to operate with simple experimental setup at room temperature [2]. As a result, the study on the thermodynamic properties of lithium and borate salt system, with isopiestic method, is an essential mean to construct thermodynamic models to predict the salt lake brine system in China as well as develop and improve the modern theory of electrolytes.

\section{The Principle of the Isopiestic Method}

Isopiestic method is generally used to the determination of water activity and osmotic coefficients of the solution, whose concentration varies from higher than $0.1 \mathrm{~mol} \cdot \mathrm{kg}^{-1}$ to the saturation concentration, the principle is with different chemical potentials of electrolyte solution was placed in a closed system, through the transfer of the solvent and eventually has the same chemical potential [3]. In the isopiestic experiments we need at least accurately know the functional relationship between concentration and water activity of a solution which works as a reference standard solution, so the water activity of the other solution can be obtained by calculation and balance of the reference standard solution of water activity. The common reference standard materials (RSM) used for isopiestic method are $\mathrm{NaCl}, \mathrm{KCl}, \mathrm{H}_{2} \mathrm{SO}_{4}$ and $\mathrm{CaCl}_{2}$. The $\mathrm{RSM}$ of $\mathrm{NaCl}$ and $\mathrm{KCl}$ are relatively cheap, easy purification and acquire more accurate data easily, but good 
applicability is presented only in the low concentration range, while $\mathrm{H}_{2} \mathrm{SO}_{4}$ and $\mathrm{CaCl}_{2}$ solution is widely used in the high concentration range [1].

\section{Thermodynamic Properties of Aqueous Solutions Containing Lithium Ions}

The research of thermodynamic properties of lithium system using isopiestic equipment is very active. Yao et al [4] used isopiestic equipment were measured water activity, osmotic coefficients of the $\mathrm{LiCl}-\mathrm{H}_{2} \mathrm{O}$ system (concentration from 0.5 to $19.8 \mathrm{~mol} \cdot \mathrm{kg}^{-1}$ ) $\mathrm{MgCl}_{2}-\mathrm{H}_{2} \mathrm{O}$ system (concentration from 0.3 to $6.0 \mathrm{~mol} \cdot \mathrm{kg}^{-1}$ ) and mixed aqueous solution (the ionic strength from 0.6 to $19.4 \mathrm{~mol} \cdot \mathrm{kg}^{-1}$ ) at $298.15 \mathrm{~K}$ and determined the solubility of $\mathrm{LiCl}$. When ionic strength is higher than $5.7 \mathrm{~mol} \cdot \mathrm{kg}^{-1}$, there are three different calculation methods to calculate the Pitzer mixing parameters. (I) introduced of the higher-order electrostatic item, (II) introduced the higher-order electrostatic item and the relations between $\theta-I$, then got the $\theta^{(0)}, \theta^{(1)}$, (III) neither of them are introduced. The results show that the method I with increasing ionic strength, $S D$ increased. (I) have little relationship between the higher-order electrostatic term and the relations of $\theta-I$, while in method III $S D$ bigger than method I, II [4]. Zhang et al [5] were determined osmotic coefficients of the $\mathrm{Li}_{2} \mathrm{SO}_{4}-\mathrm{H}_{2} \mathrm{O}$ (concentration from 0.2 to $8.7 \mathrm{~mol} \cdot \mathrm{kg}^{-1}$ ), $\mathrm{MgSO}_{4}-\mathrm{H}_{2} \mathrm{O}$ (concentration from 0.6 to $12.7 \mathrm{~mol} \cdot \mathrm{kg}^{-1}$ ) and $\mathrm{Li}_{2} \mathrm{SO}_{4}-\mathrm{MgSO}_{4}-\mathrm{H}_{2} \mathrm{O}$ mixing system (ionic strength from 1.4 to $13.5 \mathrm{~mol} \cdot \mathrm{kg}^{-1}$ ) and have verified the applicability of Pitzer equation and Scatchard equation for this system. Guo [6] et al used isopiestic equipment were measured water activity of the $\mathrm{LiCl}-\mathrm{SrCl}_{2}-\mathrm{H}_{2} \mathrm{O}$ system. $\mathrm{Li}$ [7] by using improved isopiestic apparatus were determined water activity and osmotic coefficients of $\mathrm{LiCl}-\mathrm{H}_{2} \mathrm{O}$ (concentration from 0.5 to $9.2 \mathrm{~mol} \cdot \mathrm{kg}^{-1}$ ), $\mathrm{Li}_{2} \mathrm{SO}_{4}-\mathrm{H}_{2} \mathrm{O}$ (concentration from 0.3 to 2.5 $\mathrm{mol} \cdot \mathrm{kg}^{-1}$ ) and $\mathrm{LiCl}-\mathrm{Li}_{2} \mathrm{SO}_{4}-\mathrm{H}_{2} \mathrm{O}$ (ionic strength from 0.5 to $9.5 \mathrm{~mol} \cdot \mathrm{kg}^{-1}$ ) at $273.15 \mathrm{~K}$, based on Pitzer ion interaction model and analyzed the experimental data, fitting Pitzer parameters under this temperature and modified and extended the rules of Zdanovskii, so that it can better describe the mixed system. Then Li et al [8] measured the water activity and osmotic coefficients for the same system of different concentrations at $373.15 \mathrm{~K}$ and compare to $273.15 \mathrm{~K}$ reveals the rules between osmotic coefficient and temperature, ionic strength and ion concentration fraction of $\mathrm{Li}_{2} \mathrm{SO}_{4}$. Yao et al [9] tested isopiestic equilibrium concentration and osmotic coefficient of $\mathrm{Li}_{2} \mathrm{SO}_{4}-\mathrm{K}_{2} \mathrm{SO}_{4}-\mathrm{H}_{2} \mathrm{O}$, $\mathrm{LiCl}-\mathrm{MgSO}_{4}-\mathrm{H}_{2} \mathrm{O}$ system at $348.15 \mathrm{~K}, 373.15 \mathrm{~K}$ from $0.1 \mathrm{~mol} \mathrm{~kg}^{-1}$ to near the saturation concentration range with isopiestic devices and explains the variation between the osmotic coefficient, activity coefficient, and vapor pressure, components and ionic strength. Based on the original room isopiestic apparatus, Zhang [10] formatted a device can be used in high temperature and a low temperature, then measured osmotic coefficient of $\mathrm{LiCl}-\mathrm{H}_{2} \mathrm{O}, \mathrm{MgSO}_{4}-\mathrm{H}_{2} \mathrm{O}$ binary system and $\mathrm{LiCl}-\mathrm{MgSO}_{4}-\mathrm{H}_{2} \mathrm{O}$ ternary system at $273.15 \mathrm{~K}, 298.15 \mathrm{~K}, 323.15 \mathrm{~K}, 348.15 \mathrm{~K}, 373.15$ $\mathrm{K}$. The mass of balanced solution has been corrected and the impact of air has been considered, so that the accuracy of the experimental data improved significantly. These works provide the basis data for establishing thermodynamic and dynamic model the data are listed in Table 1, 2 .

For multivariate system, Yao et al [11] also reported the research of $\mathrm{Li}^{+}, \mathrm{Na}^{+}, \mathrm{K}^{+}, \mathrm{Mg}^{2+} / / \mathrm{Cl}^{-}$, $\mathrm{SO}_{4}{ }^{2-}-\mathrm{H}_{2} \mathrm{O}$ at $298.15 \mathrm{~K}$, determined their water activity and the osmotic coefficient and compared the two kinds of thermodynamic properties. Zhou [12] the first time to forecast solubility of $\mathrm{Li}^{+}, \mathrm{K}^{+}$, $\mathrm{Mg}^{2+} / / \mathrm{SO}_{4}{ }^{2-}-\mathrm{H}_{2} \mathrm{O}$ system with the Pitzer model.

The osmotic coefficient of hybrid system has calculated by used the Pitzer model, the standard deviation of osmotic coefficient between experiment and model computation shows that isopiestic method can be well applied to study the thermodynamic properties of lithium system and provides the basis for the establishment of the model of lithium salt-water solution system. 
Tab. 1 The single salt parameters of lithium chloride and lithium sulfate at different temperatures

\begin{tabular}{ccccccc}
\hline$T(\mathrm{~K})$ & $\beta^{(0)}$ & $\beta^{(1)}$ & $C^{\Phi}$ & $m_{\max }\left(\mathrm{mol} \cdot \mathrm{kg}^{-1}\right)$ & $S D$ & $\operatorname{Ref}$ \\
\hline & & & $\mathrm{LiCl}$ & & & \\
273.15 & 0.1269 & 1.0517 & -0.00072 & 8.0 & 0.0045 & {$[7]$} \\
298.15 & 0.14503 & 0.31578 & 0.00417 & 5.704 & 0.00089 & {$[4]$} \\
298.15 & 0.15952 & 0.21017 & 0.00130 & 9.842 & 0.00828 & {$[4]$} \\
298.15 & 0.22073 & -0.52331 & -0.00817 & 19.848 & 0.04971 & {$[4]$} \\
298.15 & 0.1378 & 0.4876 & 0.00504 & 9.0 & 0.006 & {$[13]$} \\
298.15 & 0.20972 & -0.34380 & -0.00433 & 19.219 & 0.05339 & {$[14]$} \\
298.15 & 0.14667 & 0.33703 & 0.00393 & 6.0 & 0.0020 & {$[14]$} \\
323.15 & 0.1509 & 0.2709 & 0.00116 & 8.2 & 0.0028 & {$[8]$} \\
& & & $\mathrm{Li}_{2} \mathrm{SO}_{4}$ & & & \\
273.15 & 0.1561 & 0.2458 & 0.00415 & 8.0 & 0.0082 & {$[7]$} \\
298.15 & 0.14473 & 1.29952 & 0.00616 & 3.0000 & 0.00448 & {$[11]$} \\
298.15 & 0.136912 & 1.011003 & 0.00425 & 1.8972 & 0.00729 & {$[15]$} \\
323.15 & 0.1331 & 1.4904 & -0.0056 & 3.1 & 0.0015 & {$[8]$} \\
\hline
\end{tabular}

Tab. 2 The mixing ion interaction parameters for the aqueous solutions containing lithium ion systems

\begin{tabular}{|c|c|c|c|c|c|c|c|}
\hline$T(\mathrm{~K})$ & System & $\theta$ & $\varphi$ & $I\left(\mathrm{~mol} \cdot \mathrm{kg}^{-1}\right)$ & $\begin{array}{c}S D \\
\theta \neq \varphi \neq 0\end{array}$ & $\begin{array}{c}S D \\
\theta=\varphi=0\end{array}$ & Ref \\
\hline 273.15 & $\mathrm{LiCl}-\mathrm{Li}_{2} \mathrm{SO}_{4}-\mathrm{H}_{2} \mathrm{O}$ & 0.0144 & -0.003703 & 8.0 & 0.1490 & 0.0212 & [7] \\
\hline 273.15 & $\mathrm{LiCl}-\mathrm{Li}_{2} \mathrm{SO}_{4}-\mathrm{H}_{2} \mathrm{O}$ & 0.0169 & -0.003627 & 8.0 & 0.01508 & 0.0203 & [7] \\
\hline 298.15 & $\mathrm{LiCl}-\mathrm{MgCl}_{2}-\mathrm{H}_{2} \mathrm{O}$ & 0.04601 & -0.00557 & 5.694 & 0.00311 & 0.0090 & [4] \\
\hline 298.15 & $\mathrm{LiCl}-\mathrm{MgCl}_{2}-\mathrm{H}_{2} \mathrm{O}$ & 0.03829 & -0.00340 & 5.694 & 0.00301 & 0.00864 & {$[4]$} \\
\hline 298.15 & $\mathrm{LiCl}-\mathrm{MgCl}_{2}-\mathrm{H}_{2} \mathrm{O}$ & 0.06977 & -0.00826 & 5.694 & 0.00211 & 0.01301 & {$[4]$} \\
\hline 298.15 & O ${ }^{\mathrm{Li}_{2} \mathrm{SO}_{4}-\mathrm{MgSO}_{4}-\mathrm{H}_{2}}$ & 0.00039 & 0.1182 & & 0.0052 & 0.017 & {$[5]$} \\
\hline 323.15 & $\mathrm{LiCl}-\mathrm{Li}_{2} \mathrm{SO}_{4}-\mathrm{H}_{2} \mathrm{O}$ & 0.03236 & -0.01824 & 8.6 & 0.0164 & 0.0212 & {$[8]$} \\
\hline
\end{tabular}

$S D$ is the standard deviation of the fitting results by model with the experimental osmotic coefficient values.

\section{Thermodynamic Properties of Aqueous Solutions Containing Borate Ions}

When the total boron concentration is higher than $0.05 \mathrm{~mol} \cdot \mathrm{kg}^{-1}$, the reactions of polymerization and depolymerization of borates would be existed. It is difficult to predict the thermodynamic property because the effect of the total boron concentration [1]. Nowadays, when calculate the osmotic coefficient of the borate systems, the following three methods were usually used [15].

Method-I, only the ion-interaction between two ion species of $\mathrm{Li}^{+}$and $\mathrm{B}_{4} \mathrm{O}_{7}{ }^{2-}$ were considered. Yuan [15] was studied the osmotic coefficient of $\mathrm{Li}_{2} \mathrm{SO}_{4}$ (ion concentration from 0.3577 to 5.6378 $\mathrm{mol} \cdot \mathrm{kg}^{-1}$ ) $\mathrm{Li}_{2} \mathrm{~B}_{4} \mathrm{O}_{7}$ (ion concentration from 0.1757 to $2 \mathrm{~mol} \cdot \mathrm{kg}^{-1}$ ) and mixed salt aqueous solution (ionic strength from 0.3118 to $5.5248 \mathrm{~mol} \cdot \mathrm{kg}^{-1}$ ) and osmotic coefficient of the system is changing with the ionic strength. In order to better describe the polymerization and depolymerization reaction to join the $\beta^{(2)}$ and change the $\mathrm{a}_{2}$ of Pitzer equation. Yin [16] also adopted the method I when determination $\mathrm{MgSO}_{4}-\mathrm{MgB}_{4} \mathrm{O}_{7}$. While method-I is possible to describe the borate salt system but ignored the balance of the polymerization and depolymerizationboron. Method-II based on chemical equilibrium and Pitzers equations of osmotic coefficient for mixed electrolytes. Zhang [17] has used three methods to research the $\mathrm{Li}_{2} \mathrm{~B}_{4} \mathrm{O}_{7}-\mathrm{H}_{2} \mathrm{O}$ systems, the research shows that method-II can reflect the internal of $\mathrm{Li}_{2} \mathrm{~B}_{4} \mathrm{O}_{7}$ solution. Yang et al [18-20] $\mathrm{LiCl}-\mathrm{Li}_{2} \mathrm{~B}_{4} \mathrm{O}_{7}-\mathrm{H}_{2} \mathrm{O}$ system under the different temperature is studied, on the basis of the original model modified, at $m<0.08 \mathrm{~mol} \cdot \mathrm{kg}^{-1}$, the species $\mathrm{H}_{3} \mathrm{BO}_{3}, \mathrm{~B}(\mathrm{OH})_{4}{ }^{-}, \mathrm{Li}^{+}, \mathrm{Cl}^{-}$were considered, but at $m \geq 0.08 \mathrm{~mol} \cdot \mathrm{kg}^{-1}$, the species $\mathrm{H}_{3} \mathrm{BO}_{3}, \mathrm{~B}_{3} \mathrm{O}_{3}(\mathrm{OH})_{4}{ }^{-}, \mathrm{B}(\mathrm{OH})_{4}{ }^{-}, \mathrm{Li}^{+}$, $\mathrm{Cl}^{-}$were considered. In the estimations of the ion interaction parameters the $\mathrm{H}_{3} \mathrm{BO}_{3}$ was neglected. Table 3 lists the Pitzer single salt parameters of the system under different temperature.

For the convenience in applying, we simplify the method II, merge the similar coefficient. Zhang et al [21] at $298.15 \mathrm{~K}$ under research $\mathrm{Li}_{2} \mathrm{~B}_{4} \mathrm{O}_{7}-\mathrm{MgCl}_{2}(\mathrm{~B})-\mathrm{H}_{2} \mathrm{O}$ system adopts the $\theta_{\mathrm{XT}}$ express combined action of the three kinds of boric acid salt and some kind of positive ion. The $\theta_{\mathrm{BT}, \mathrm{X}}$ said any one of the three kinds of boric acid salt combination of interaction; $\varphi_{\mathrm{Mg}, \mathrm{Cl}, \mathrm{BT}}$ express combined 
action of the three kinds of boric acid salt and positive ion. $\varphi_{\mathrm{Mg} \mathrm{Li} \mathrm{BT}}$ express combined action of the three kinds of $\mathrm{Li}^{+}, \mathrm{Mg}^{2+}$.

Tab. 4 Relative deviations of the calculated and experimental osmotic coefficients of borate systems

\begin{tabular}{clccc}
\hline$T(\mathrm{~K})$ & \multicolumn{1}{c}{ System } & $\mathrm{RSM}$ & $R D$ & Ref \\
\hline 298.15 & $\mathrm{LiSO}_{4}-\mathrm{Li}_{2} \mathrm{~B}_{4} \mathrm{O}_{7}-\mathrm{H}_{2} \mathrm{O}$ & $\mathrm{NaCl}(\mathrm{aq})$ & 0.02 & {$[15]$} \\
298.15 & $\mathrm{Li}_{2} \mathrm{~B}_{4} \mathrm{O}_{7}-\mathrm{H}_{2} \mathrm{O}$ & $\mathrm{NaCl}(\mathrm{aq})$ & 0.01 & {$[17]$} \\
273.15 & $\mathrm{LiCl}-\mathrm{Li}_{2} \mathrm{~B}_{4} \mathrm{O}_{7}-\mathrm{H}_{2} \mathrm{O}$ & $\mathrm{NaCl}(\mathrm{aq})$ & $<0.04$ & {$[18]$} \\
298.15 & $\mathrm{LiCl}-\mathrm{Li}_{2} \mathrm{~B}_{4} \mathrm{O}_{7}-\mathrm{H}_{2} \mathrm{O}$ & $\mathrm{NaCl}(\mathrm{aq})$ & $<0.04$ & {$[19]$} \\
298.15 & $\mathrm{LiCl}-\mathrm{Li}_{2} \mathrm{~B}_{4} \mathrm{O}_{7}-\mathrm{H}_{2} \mathrm{O}$ & $\mathrm{NaCl}(\mathrm{aq})$ & $<0.01$ & {$[20]$} \\
298.15 & $\mathrm{Li}_{2} \mathrm{~B}_{4} \mathrm{O}_{7}-\mathrm{MgCl}_{2}(\mathrm{~B})-\mathrm{H}_{2} \mathrm{O}$ & $\mathrm{NaCl}(\mathrm{aq})$ & $<0.05$ & {$[21]$} \\
\hline
\end{tabular}

$R D$ is the relative deviation of fitting results with the experimental osmotic coefficient values.

It should be pointed out is that method-I has a less of parameters and easy to be used. Method-II and III considering the single boron, three boron and four boron species, has a lot of parameters but is more a reflection of internal reaction of the borate salt ions, we should to analysis when using the above three methods.

\section{Conclusion}

Based on a brief introduction to isopiestic technical analysis, the isopiestic researches of thermodynamic properties of the aqueous systems containing lithium and borate were introduced, the Pitzer single salt parameters and mixed ion interaction parameters of chloride and sulfate containing lithium at different temperatures and systems were summarized, and new progresses on the isopiestic on borates had been also raised, which is of great importance to promote the thermodynamic modulus of the complex lake brine systems containing lithium and boron ions. It is also worth noting that isopiestic study on thermodynamic properties of electrolyte solutions, which are mostly concentrated at normal temperature and pressure, with a narrow temperature range. As for the borate containing alkali metals and alkaline earth metal, the researches on thermodynamic properties are still very deficient, how to express the thermodynamic properties of the borate systems within a wide range of concentration and expand the thermodynamic model of borate electrolyte solutions is the main direction of future development.

\section{Acknowledgment}

Financial support from NNSFCs (21306136, 21406104, U1407113 and U1507112), Postdoctoral Science Foundation (2015M581303 and 2016M592827) and the Laboratory Foundation of Chinese Universities (SY2015018) is acknowledged.

\section{References}

[1] Jimin Yang. Isopiestic studies of the thermodynamic property of $\mathrm{LiCl}-\mathrm{Li}_{2} \mathrm{~B}_{4} \mathrm{O}_{7}-\mathrm{H}_{2} \mathrm{O}$ at different temperatures[D]. Xining: Qinghai Institute of Salt Lakes, 2004.

[2] Tianlong Deng, Huan Zhou, Xia Chen. Salt-Water system phase diagrams and applications[M]. Beijing: Chemical Industry Press, 2013.

[3] Tianlong Deng, Yan Yao, Zhenying Zhang, et al. Isopiestic studies of the thermodynamic property of $\mathrm{NaCl}-\mathrm{CaCl}_{2}-\mathrm{H}_{2} \mathrm{O}$ at $T=308.15 \mathrm{~K}[\mathrm{~J}]$. Scientia Sinica Chimica, 2010 40(7) 1371-1377.

[4] Yan Yao, Bo Sun, Pengsheng Song, et al. The isopiestic researchs of thermodynamic properties of water and salt systems containing lithium: Isopiestic studies of osmotic and activity coefficients of LiCl- $\mathrm{MgCl}_{2}-\mathrm{H}_{2} \mathrm{O}[\mathrm{J}]$. Acta Chimica Sinica, 199250 839-848.

[5] Zhong Zhang, Yan Yao, Pengsheng Song, et al. Isopiestic studies of osmotic and activity coefficients of $\mathrm{Li}_{2} \mathrm{SO}_{4}-\mathrm{MgSO}_{4}-\mathrm{H}_{2} \mathrm{O}[\mathrm{J}]$. Acta Physico-Chimica Sinica. 19939 366-373. 
[6] Lijiang Guo, Bai Sun, Dewen Zeng, et al. Isopiestic measurement and solubility evaluation of the ternary system $\mathrm{LiCl}-\mathrm{SrCl}_{2}-\mathrm{H}_{2} \mathrm{O}$ at $298.15 \mathrm{~K}[\mathrm{~J}]$. Journal of Chemical and Engineering Data, 2012 57(3) 817-827.

[7] Feifei Li,Yan Yao. Isopiestic studies of the thermodynamic property of $\mathrm{LiCl}-\mathrm{Li}_{2} \mathrm{SO}_{4}-\mathrm{H}_{2} \mathrm{O}$ at $T$ = 273.15 K[J]. Chemical Research and Application, 2004 16(1) 33-36.

[8] Feifei Li,Yan Yao. Isopiestic studies of the thermodynamic property of $\mathrm{LiCl}-\mathrm{Li}_{2} \mathrm{SO}_{4}-\mathrm{H}_{2} \mathrm{O}$ at $T$ = 323.15 K[J]. Journal of Salt Lake Research, 2004 12(1) 37-42.

[9] YanYao, Qi Zhang, Pengsheng Song. Isopiestic researchs of thermodynamic properties of $\mathrm{Li}_{2} \mathrm{SO}_{4}-\mathrm{K}_{2} \mathrm{SO}_{4}-\mathrm{H}_{2} \mathrm{O}$ and LiCl-MgSO $4-\mathrm{H}_{2} \mathrm{O}[\mathrm{J}]$. Chemical World, 19963732.

[10] Qi Zhang, Dongdong Li, Yan Yao, et al. Isopiestic determination of aqueous LiCl- $\mathrm{MgSO}_{4}-\mathrm{H}_{2} \mathrm{O}$ at $T=298.15$ to $373.15 \mathrm{~K}$ and representation with pitzer model[J]. The $5^{\text {th }}$ national symposiu on thermal analysis kinetics and thermokinetics of chinese chemical society, 201430.

[11] Yan Yao, Pengsheng Song, Qi Zhang. The prediction of permeability coefficient activity coefficient and saturation for $\mathrm{Li}^{+}, \mathrm{Na}^{+}, \mathrm{K}^{+} / / \mathrm{Cl}^{-} \mathrm{SO}_{4}{ }^{2-}-\mathrm{H}_{2} \mathrm{O}$ system of qinghai yi li ping lake at $\mathrm{T}=25^{\circ} \mathrm{C}[\mathrm{J}]$. Oceanologia Et Limnologia Sinica, 19991 6-13.

[12] Hongyan Zhou, Dengwen Ceng, Haijun Han, et al. Pitzer model for prediction of solubilities for $\mathrm{Li}^{+}, \mathrm{K}^{+}, \mathrm{Mg}^{2+} / / \mathrm{SO}_{4}{ }^{2-}-\mathrm{H}_{2} \mathrm{O}$ at T = $273.15 \mathrm{~K}[\mathrm{~J}]$ Journal of Salt Lake Research, 2013 21 49-45.

[13] Yigui Li. Thermodynamics of solvent extraction of metals[M] Beijing: Tsinghua University press, 199590.

[14] Heetaik Kim, WilliamJ FrederickJr. Evaluation of pitzer ion interaction parameters of aqueous mixed electrolyte solutions at $25^{\circ} \mathrm{C}$ ternary mixing parameters[J]. Journal of the Chemical and Engineering Data, 198833 177-278.

[15] WenpingYuan, Yan Yao, Pengsheng Song. Isopiestic determination of the thermodynamic property for $\mathrm{Li}_{2} \mathrm{SO}_{4}-\mathrm{Li}_{2} \mathrm{~B}_{4} \mathrm{O}_{7}-\mathrm{H}_{2} \mathrm{O}$ at $T=298.15 \mathrm{~K}[\mathrm{~J}]$. Journal of Salt Lake Research, 200513 29-34.

[16] Songtao Yin, Yan Yao, Bo $\mathrm{Li}$, et al. Isopiestic determination of aqueous $\mathrm{MgB}_{4} \mathrm{O}_{7}$ and $\mathrm{MgSO}_{4}-\mathrm{MgB}_{4} \mathrm{O}_{7}$ at $298.15 \mathrm{~K}$ and representation with pitzer ion interaction model[J]. Journal of Solution Chemistry, 2007361 7457-7461.

[17] Aiyun Zhang, Yan Yao, Lijuan Li, et al. Isopiestic determination of the osmotic coefficients and pitzer model representation for $\mathrm{Li}_{2} \mathrm{~B}_{4} \mathrm{O}_{7}(\mathrm{aq})$ at $T=298.15 \mathrm{~K}[\mathrm{~J}]$. Journal of Chemical Thermodynamics, 200537 1101-1109.

[18] Jinmin Yang, Yan Yao. Isopiestic determination of the osmotic coefficients and Pitzer model representation for the $\mathrm{LiCl}-\mathrm{Li}_{2} \mathrm{~B}_{4} \mathrm{O}_{7}-\mathrm{H}_{2} \mathrm{O}$ system at $T=298.15 \mathrm{~K}[\mathrm{~J}]$. Acta Chimica Sinica, 200765 1089-1093.

[19] Jimin Yang, Yan Yao, Aiyun Zhang, et al. Isopiestic determination of the thermodynamic property for $\mathrm{LiCl}-\mathrm{Li}_{2} \mathrm{~B}_{4} \mathrm{O}_{7}-\mathrm{H}_{2} \mathrm{O}$ at $\mathrm{T}=298.15 \mathrm{~K}[\mathrm{~J}]$. Chemical Research in Chinese Universities, 200627 735-738.

[20] Jimin Yang, Yan Yao, Qiyang Xia, et al. Isopiestic determination of the osmotic coefficients and Pitzer model representation for the $\mathrm{Li}_{2} \mathrm{~B}_{4} \mathrm{O}_{7}-\mathrm{LiCl}-\mathrm{H}_{2} \mathrm{O}$ system at $T=298.15 \mathrm{~K}[\mathrm{~J}]$. Journal of Solution Chemistry, 2008 37(3) 377-389.

[21] Aiyun Zhang, Yan Yao, Jimin Yang, et al. Isopiestic determination of the thermodynamic property and Pitzer model representation for $\mathrm{Li}_{2} \mathrm{~B}_{4} \mathrm{O}_{7}-\mathrm{MgCl}_{2}(\mathrm{~B})-\mathrm{H}_{2} \mathrm{O}[\mathrm{J}]$. Acta Chimica Sinica, 200462 1089-1094. 